Journal of The Magnetics Society of Japan Vol. 13, Supplement, No. S1 (1989)

(C) 1989 by The Magnetics Society of Japan

\title{
RECORDING CHARACTERISTICS OF PARTIALLY OXIDIZED Fe-CO MEDIA WITH AN Fe-CO UNDER-LAYER
}

S.NASU, K.MATSUMOTO, A.NAKAJIMA, M. ISURUGI, K.SAIKI

Central Res.Lab. ,Kanegafuchi Chemical Ind.Co., Ltd.

2-80,1-chome, Yoshida-cho,Hyogo-ku, Kobe, 652, Japan

Abstract --- Recording characteristics of partially oxidized Fe-Co media were improved remarkably by the introduction of an Fe-Co under-layer. In this paper, the effects of the coercive force of the Fe-Co under-layer on recording characteristics were investigated using a ring-type head. The stronger the coercive force of the under-layer, the higher the reproduced voltage and recording density D50, and the superior C/N and overwrite characteristics. Waveforms of a medium whose Fe-Co under-layer possessed a high coercive force were sharper than those of a medium with low coercive force. We consider that the broadening of the waveforms depends mainly on interactions between the head and Fe-Co under-layer.

\section{INTRODUCTION}

Perpendicular magnetic recording is promising as a key technology for high density recording systems. $\mathrm{Co}-\mathrm{Cr}$ thin film media developed for these systems, however, are not durable enough for practical use. We reported previously that partially oxidized Fe-Co media ( $\mathrm{Fe}-$ Co-O) prepared by $R F$ reactive magnetron sputtering have a large perpendicular anisotropy, a large saturation magnetization(1) and good durability (2). We also reported the recording characteristics of $\mathrm{Fe}-\mathrm{Co}-\mathrm{O}$ media using a ring-type head(3). In addition, we reported that the reproduced voltage can be increased further for $\mathrm{Fe}-$ $\mathrm{CO}-\mathrm{O}$ media by introducing an $\mathrm{Fe}-\mathrm{Co}$ underlayer ( $\mathrm{Fe}-\mathrm{Co}-\mathrm{O} / \mathrm{Fe}-\mathrm{Co})$ using a ring-type head(4). The optimum thicknesses of the Fe$\mathrm{Co}$ under-layer and $\mathrm{Fe}-\mathrm{CO}-\mathrm{O}$ were $500 \mathrm{~A}$ and $1500 \mathrm{~A}$, respectively. It has already been reported that decreasing the demagnetization field enhanced the reproduced voltage by introducing a soft magnetic underlayer $(5)(6)$. We believe, however, that the recording characteristics of this medium were influenced by the coercive force (Hc) of the Fe-Co under-layer as well as the decreasing the demagnetization field.

In this paper, the effects of $\mathrm{Hc}$ of $\mathrm{Fe}-$ $\mathrm{Co}$ under-layers on the reconding characteristics were investigated.

\section{MEDIA PREPARATION AND MEASUREMENT METHODS}

Fe-Co-O layers and $\mathrm{Fe}-\mathrm{Co}$ under-layers were prepared by $R F$ reactive- and $R F$ magnetron sputtering, respectively. The sputtering target for $\mathrm{Fe}-\mathrm{CO}-\mathrm{O}$ preparation was Fe-Co alloy, whose diameter and Co content were 6 inches and 40 at. $\frac{0}{6}$. The anisotropy field and coercive force in the perpendicular direction have maximum values at $\mathrm{Co} 40$ at. $\frac{\%}{o}$ for an $\mathrm{Fe}-\mathrm{Co}-\mathrm{O}$ single-layered medium. The sputtering target for $\mathrm{Fe}$-Co under-layer preparation was also Fe-Co alloy, whose diameter was 6 inches, and Co content was varied. Polyimide film with $50 \mu \mathrm{m}$ thickness was used as the substrate. The oxidation for $\mathrm{Fe}-\mathrm{Co}-\mathrm{O}$ layer was controlled by oxygen pressure and sputtering rate $(20-30 \mathrm{~A} / \mathrm{sec})$.

Media were prepared by rotating the substrate above the target. Thicknesses of $\mathrm{Fe}-\mathrm{Co}-\mathrm{O}$ and $\mathrm{Fe}-\mathrm{Co}$ under-layer were controlled to be $1500 \mathrm{~A}$ and $500 \mathrm{~A}$, respectively.

Recording characteristics were measured by a spectrum analyzer and a flexible disc measurement system using a Mn-Zn-ferrite ring-type head whose gap length,track width and coil turn number were $0.3 \mu \mathrm{m}$, $30 \mu \mathrm{m}$ and 20 , respectively. 


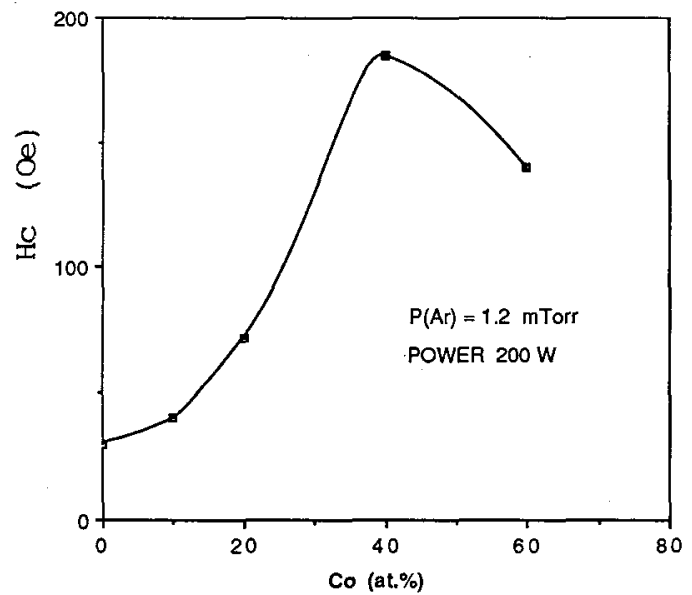

Fig.1 Co content dependence of $\mathrm{Hc}$

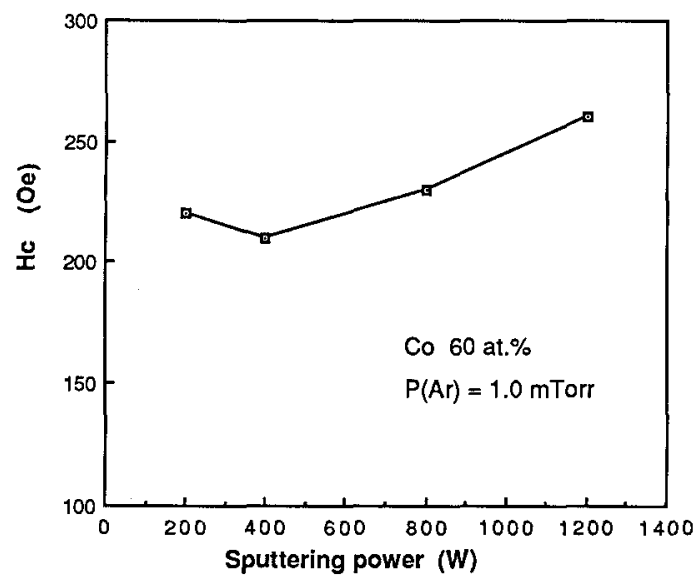

Fig.2 Sputtering power dependence of $\mathrm{Hc}$ of $\mathrm{Fa}-\mathrm{Co}$ under-layer.

\section{RESULTS AND DISCUSSION}

\section{$3.1 \mathrm{HC}$ of $\mathrm{Fe}$-Co under-layer}

$\overline{\mathrm{HC}}$ of the $\mathrm{Fe}-\mathrm{Co}$ under-layer depends on Co content of the target, power and pressure during sputtering. Fig.1 shows Co content dependence of $\mathrm{HC}$ in the fixed conditions of Ar pressure of 1.2 mTorr and sputtering power of $200 \mathrm{~W}$. HC was measured in the track direction. The difference between $\mathrm{HC}$ of track direction and that of

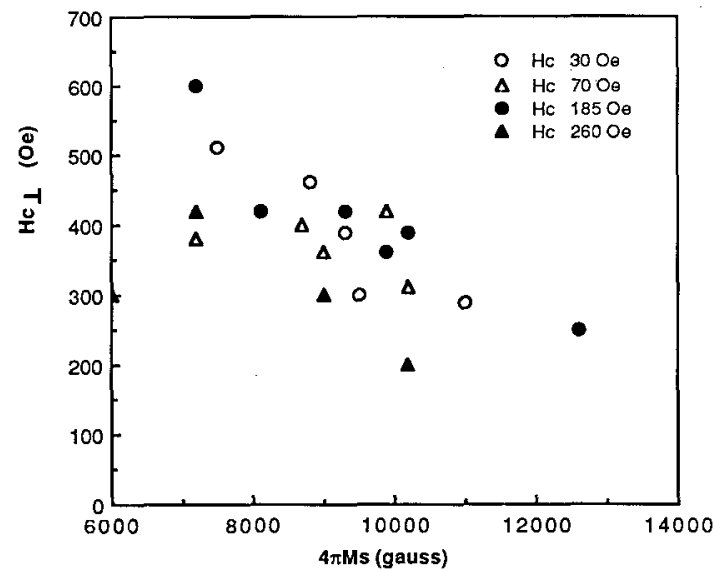

Fig.3 Relationship between perpendicular coercive force $\mathrm{Hc} \perp$ and saturation magnetization $4 \pi \mathrm{Ms}$.

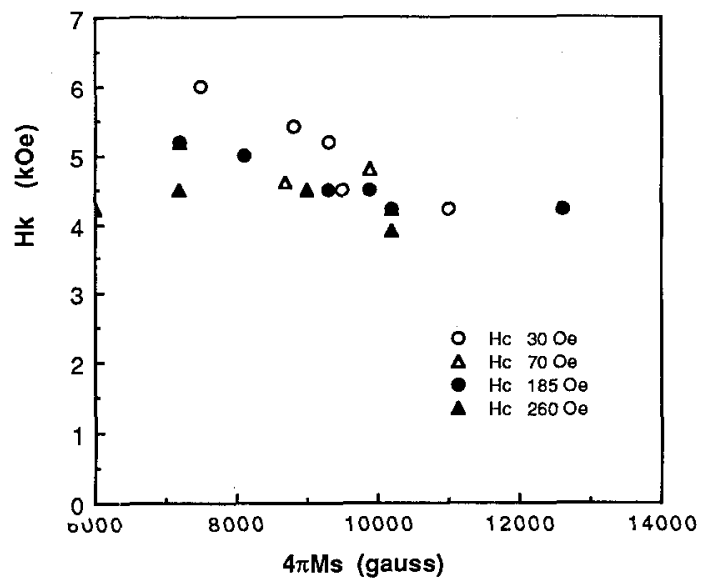

Fig.4 Relationship between anisotropy field $\mathrm{Hk}$ and $4 \pi \mathrm{Ms}$.

track width direction was very small. HC depends on the Co content and becomes maximum at 40 at.\%. Fig.2 shows the relationship between $\mathrm{HC}$ and sputtering power for Co 60 at.\%. Hc increases with increasing sputtering power. The structure of the films described above was analyzed by X-ray diffraction method. It was orientated to bcc(110). 
3.2 Magnetic properties of $\mathrm{Fe}-\mathrm{Co}-\mathrm{O} / \mathrm{Fe}-\mathrm{Co}$ Fig.s 3 and 4 show the relationships between perpendicular coercive force ( $\left.\mathrm{HCl}_{\perp}\right)$, anisotropy field $(\mathrm{Hk})$ and $4 \pi \mathrm{Ms}$ (oxidation degree) of the $\mathrm{Fe}-\mathrm{Co}-\mathrm{O}$ layer with varying Co content of $\mathrm{Fe}-\mathrm{Co}$ underlayer, which were measured without separation of each layer. In this case, Hc of the under-layer was changed from 30 to 185 Oe by varying the Co content from 0 to 40 at. $\frac{\circ}{5}$ and under-layers possessing $\mathrm{HC}$ of 260 Oe were prepared at sputtering power of $1200 \mathrm{~W}$ using Co 60 at.\% target. Both $\mathrm{HC}_{\perp}$ and $\mathrm{Hk}$ of $\mathrm{Fe}-\mathrm{Co}-\mathrm{O} / \mathrm{Fe}-\mathrm{Co}$ double layers depend mainly on $4 \pi \mathrm{Ms}$ of $\mathrm{Fe}-\mathrm{Co}-\mathrm{O}$.

\subsection{Recording characteristics}

For the measurement of recording characteristics, the recording current was selected at $4 \mathrm{~mA}$, because the reproduced voltage of all media saturated at $4 \mathrm{~mA}$. Fig.5 shows the relationship between normalized reproduced voltage $(V)$ at a recording density of $25.4 \mathrm{kfci}$ and $4 \pi \mathrm{Ms}$ of $\mathrm{Fe}-\mathrm{Co}-\mathrm{O}$ layer with varying $\mathrm{HC}$ of the $\mathrm{Fe}-\mathrm{CO}$ under-layer from 30 to 260 De. V for every $\mathrm{HC}$ of the Fe-Co under-layer shows the maximum value at $4 \pi \mathrm{Ms}$ of 9000 gauss. In addition, the maximum value increases with increasing $\mathrm{Hc}$ of $\mathrm{Fe}-\mathrm{Co}$ under-layer. Fig. 6 shows the relationship between recording density D50 and $4 \pi \mathrm{Ms}$ of the $\mathrm{Fe}-$ $\mathrm{Co}-\mathrm{O}$ layer. D50 for every $\mathrm{Hc}$ of the Fe-Co under-layer also shows maximum value at $4 \pi M s$ of 9000 gauss, and the maximum value increases with increasing $\mathrm{Hc}$. The best $\mathrm{V}$ ( $170 \mu \mathrm{VO}-\mathrm{p} / \mathrm{mm} /(\mathrm{m} / \mathrm{sec}) / \mathrm{turn})$ and D50 (82 $\mathrm{kfci}$ ) were acquired for $4 \pi \mathrm{Ms}$ of 9000 gauss and $\mathrm{Hc}$ of $260 \mathrm{Oe}$.

The result that $V$ increases with increasing $4 \pi \mathrm{Ms}$ proportionally is similar to that of $\mathrm{Fe}-\mathrm{Co}-\mathrm{O}$ single-layered media. Namely, $V$ is proportional to $4 \pi \mathrm{Ms}$ for media having $4 \pi$ is less than 9000 gauss, however, $\mathrm{Hc}$ is so small that $\mathrm{V}$ decreases for media having $4 \pi$ Ms more than 9000 gauss.

It is impossible to explain the increase of $\mathrm{V}$ with Hc of the under-layer only by a decrease of demagnetization.

\subsection{Waveform}

Reproduced waveforms were investigated by varying $\mathrm{HC}$ of the $\mathrm{Fe}-\mathrm{Co}$ under-layer.

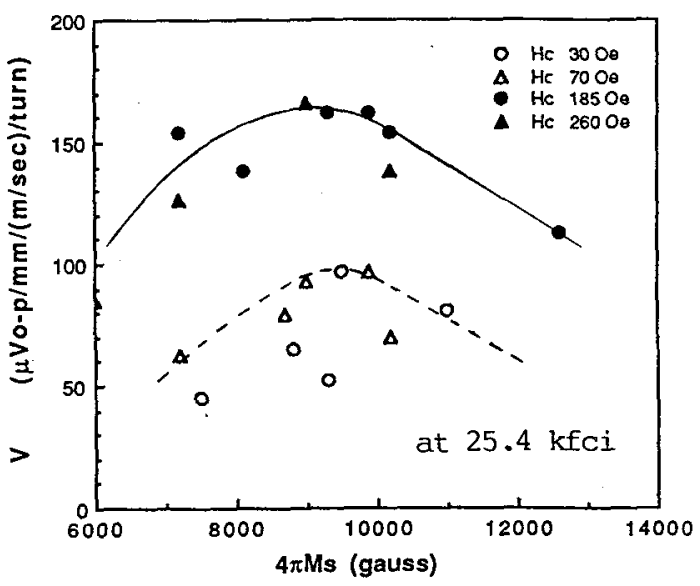

Fig.5 Relationship between normalized reproduced voltage $V$ and $4 \pi \mathrm{Ms}$.

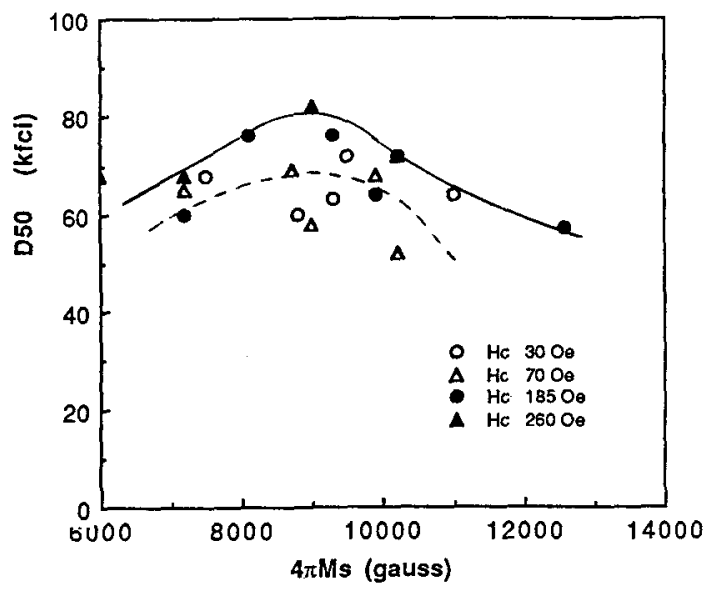

Fig.6 Relationship between recording density D50 and $4 \pi \mathrm{Ms}$

for media possessing $\mathrm{Fe}-\mathrm{Co}-\mathrm{O}$ layers whose $4 \pi \mathrm{Ms}$ was 9000 gauss. The magnetic properties of the media are shown in Table 1. $\mathrm{HC}$ " in Table 1 denotes the coercive force measured in a longitudinal direction for double-layered medium. Fig.7 shows the waveforms when $\mathrm{HC}$ of the $\mathrm{Fe}-\mathrm{Co}$ underlayer and recording current were varied. From Fig.7, the following facts are revealed. 

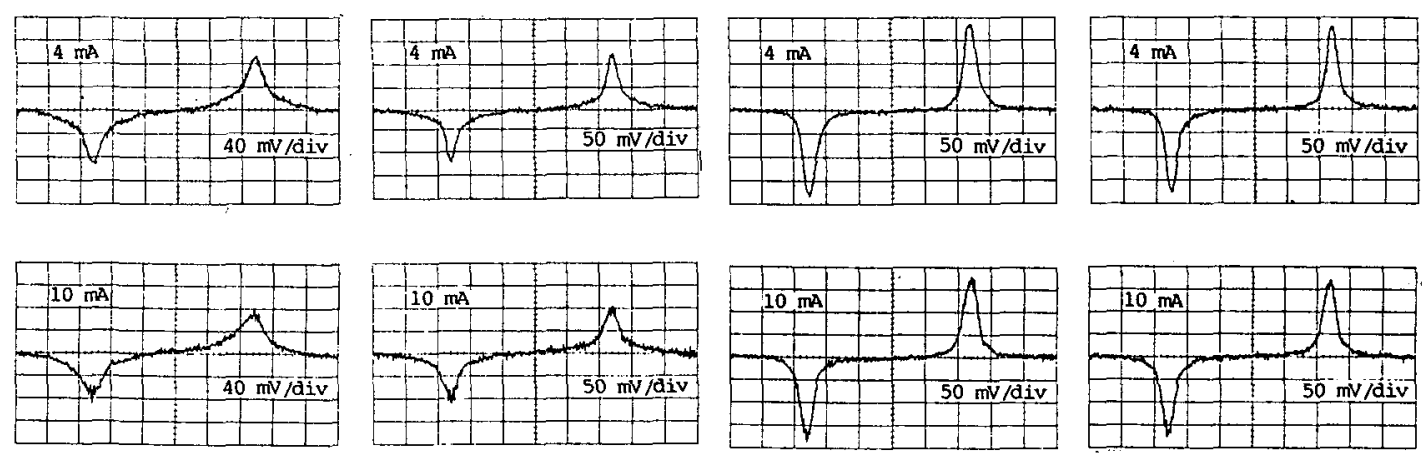

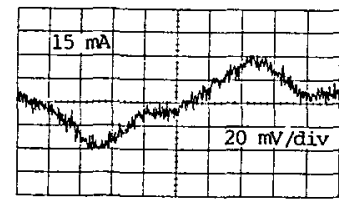

Medium A

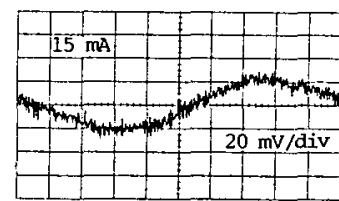

Medium B

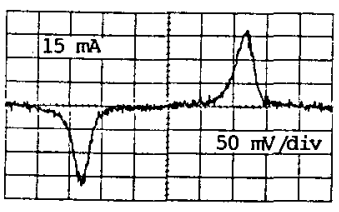

Medium C

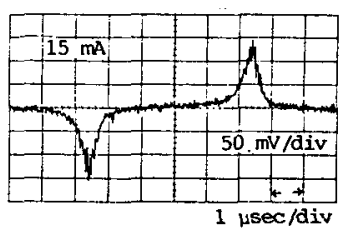

Medium D

Fig.7 Waveforms of Fe-Co-O/Fe-Co double-layered media.

Table 1 Magnetic properties of $\mathrm{Fe}-\mathrm{Co}-\mathrm{O} / \mathrm{Fe}-\mathrm{Co}$ double-layered media. Hc; ccercive force of $\mathrm{Fe}-\mathrm{Co}$ under-layer, $\mathrm{Hc}_{1}$; coercive force of perpendicular direction, $\mathrm{Hc} / /$; coercive force of longitudinal direction.

\begin{tabular}{|c|c|c|c|c|}
\hline & Hc (Oe) & $\mathrm{Hc}_{\perp}(\mathrm{Oe})$ & $\mathrm{Hc} /(\mathrm{Oe})$ & $\begin{array}{c}4 \pi \text { MS } \\
\text { (gauss) }\end{array}$ \\
\hline Medium A & 30 & 460 & 70 & 8800 \\
\hline Medium B & 70 & 400 & 140 & 8700 \\
\hline Medium C & 185 & 420 & 240 & 9300 \\
\hline Medium D & 260 & 300 & 220 & 9000 \\
\hline
\end{tabular}

1) The waveform becomes sharper with increasing $\mathrm{Hc}$ at the same recording current.

2) The waveform broadens drastically with decreasing $\mathrm{HC}$ as the recording current becomes higher.

The broadening of the waveform might be caused by interaction between the Fe-Co under-layer and head. The permeability $\mu$ of the Fe-Co under-layer changes with $\mathrm{HC}$ under a constant $4 \mathrm{mMs}$ of $\mathrm{Fe}-\mathrm{Co}$. For low Hc, it is considered that the head field becomes broad, because of strong interaction between the Fe-Co under-layer and head. Therefore, the magnetization transition was broadened by the effect of both broadened writing head field and low $\mathrm{HC}$, resulting in decrease of $\mathrm{V}$ and $\mathrm{D} 50$. on the other hand, for high $\mathrm{Hc}$, it is considered that the head field does not broaden, even at high recording currents. Therefore, the magnetization transition remains narrow, so both $\mathrm{V}$ and $\mathrm{D} 50$ are high.

In spite of the fact that $\mathrm{Hc}$ of Medium D is higher than that of Medium $C$, the degree of $V$ decreasing is large with increasing recording current in Fig.7. This result is due to recording demagnetization because of low $\mathrm{Hc}_{\perp}$.

Fig. 8 shows waveform changes with varying recording currents and $4 \pi \mathrm{Ms}$ of a medium having a constant $\mathrm{Hc}$ of $260 \mathrm{Oe}$. For a recording current of $4 \mathrm{~mA}$, the waveform is sharpest at $4 \pi \mathrm{Ms}$ of 9000 gauss. $4 \pi \mathrm{Ms}$ larger than 9000 gauss or less than 9000 gauss broadens the waveforms. In addition, although the waveforms broaden with increasing recording current, broadening of the waveform at $4 \pi \mathrm{Ms}$ of 9000 gauss is the smallest. It is considered that the 

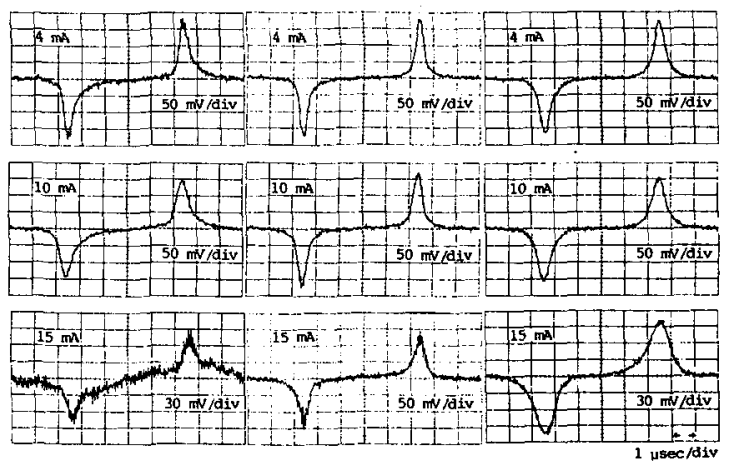

(a)

(b)

(c)

Fig. 8 Waveforms of $\mathrm{Fe}-\mathrm{Co}-\mathrm{O} / \mathrm{Fe}-\mathrm{Co}$ double-layered media with varying $4 \mathrm{mMs}$ of $\mathrm{Fe}-\mathrm{Co}-\mathrm{O}$. (a) $4 \mathrm{mMs}$ of 7200 gauss, (b) 9000 gauss, (c) 10200 gauss.

broadened waveform of the medium whose $4 \pi \mathrm{Ms}$ is 10200 gauss, originates from the wider magnetization transition generated by low $\mathrm{HC}_{1}$. On the other hand, waveform broadening at $4 \pi \mathrm{Ms}$ of 7200 gauss might indicate that capacity of the head is insufficient for high $\mathrm{HC}_{\perp}$ or high $\mathrm{Hk}$ medium. It is considered that there are optimum magnetic properties for each layer of media, and an optimum combination between magnetic properties of the medium and head.

\section{$3.5 \mathrm{C} / \mathrm{N}$ and overwrite characteristics}

Fig. 9 shows the relationship between $\mathrm{C} / \mathrm{N}$ at a recording density of $25.4 \mathrm{kfci}$ and $4 \pi \mathrm{Ms}$ of the $\mathrm{Fe}-\mathrm{Co}-\mathrm{O}$ layer, where $\mathrm{Hc}$ of under-layer was varied. Resolution bandwidth was $30 \mathrm{kHz}$. The higher $\mathrm{Hc}$ of Fe-Co under-layer, the higher $C / N$. C/N obtained at $4 \pi \mathrm{Ms}$ of 9000 gauss and $\mathrm{Hc}$ of 260 De is about $42 \mathrm{~dB}$. The improvement of $\mathrm{C} / \mathrm{N}$ is mainly due to an increase of signal intensity.

Overwrite characteristics(O-W) were measured using the above-mentioned head at relative velocity of $2 \mathrm{~m} / \mathrm{sec}$. $\mathrm{O}-\mathrm{W}$ were measured as the ratio of residual level of $2 \mathrm{~F}(40 \mathrm{kfci}, 1.6 \mathrm{MHz})$ signals to initial $2 \mathrm{~F}$ level after overwriting $1 \mathrm{~F}(20 \mathrm{kfci}, 0.8 \mathrm{MHz})$ signals on $2 \mathrm{~F}$ signals. Fig.10 (a), (b) show recording current dependence of $\mathrm{O}-\mathrm{W}$ and recording-reproducing characteristics for $\mathrm{HC}$ of $260 \mathrm{Oe}$ and $\mathrm{Hc}$ of $30 \mathrm{Oe}$. O-W decrease with increasing recording current

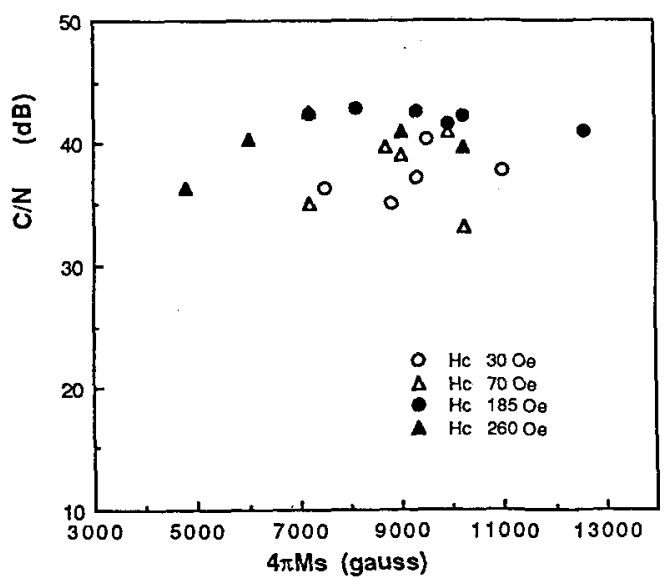

Fig. $94 \pi \mathrm{Ms}$ dependence of $\mathrm{C} / \mathrm{N}$.

but $\mathrm{O}-\mathrm{W}$ for $\mathrm{HC}$ of 260 De increase again at $10 \mathrm{~mA}$. The result closely relates to the demagnetization shown in Fig.10(b). Furthennore, $O-W$ for $\mathrm{Hc}$ of 260 Oe are superior to those of $\mathrm{Hc}$ of $30 \mathrm{De}$, about-28 $\mathrm{dB}$. The difference of $\mathrm{O}-\mathrm{W}$ between for low $\mathrm{Hc}$ and for high $\mathrm{HC}$ is not caused by the difference of recording sensitivity for each recording density, because it is almost same as shown in Fig.10 (b). It is considered that the difference is caused by broadening of the head field.

\section{CONCLUSION}

Recording characteristics for Fe-Co$\mathrm{O} / \mathrm{Fe}-\mathrm{Co}$ media in which $\mathrm{Hc}$ of the Fe-Co under-layer and $4 \pi \mathrm{Ms}$ of $\mathrm{Fe}-\mathrm{Co}-\mathrm{O}$ layer were varied, were investigated. Both reproduced voltage $\mathrm{V}$ and recording density D50 for high $\mathrm{Hc}$ were higher than those of low $\mathrm{Hc}$. $\mathrm{V}$ and $\mathrm{D} 50$ for $\mathrm{HC}$ of 260 De and $4 \pi \mathrm{Ms}$ of 9000 gauss were about $170 \mu \mathrm{Vo}-\mathrm{p} / \mathrm{mm} /(\mathrm{m} / \mathrm{sec})$ /turn and $82 \mathrm{kfci}$, respectively.

$\mathrm{C} / \mathrm{N}$ and $\mathrm{O}-\mathrm{W}$ of the media whose $\mathrm{Fe}-\mathrm{CO}$ under-layer possessed high $\mathrm{Hc}(260 \mathrm{De})$ and $4 \pi \mathrm{Ms}$ of 9000 gauss, were $42 \mathrm{~dB}$ and $-28 \mathrm{~dB}$, respectively, in the conditions of recording density of $25.4 \mathrm{kfci}$, relative velocity of $2 \mathrm{~m} / \mathrm{sec}$ and track width of 30 um.

Isolated waveforms were compared. The medium with low Hc under-layer showed the 


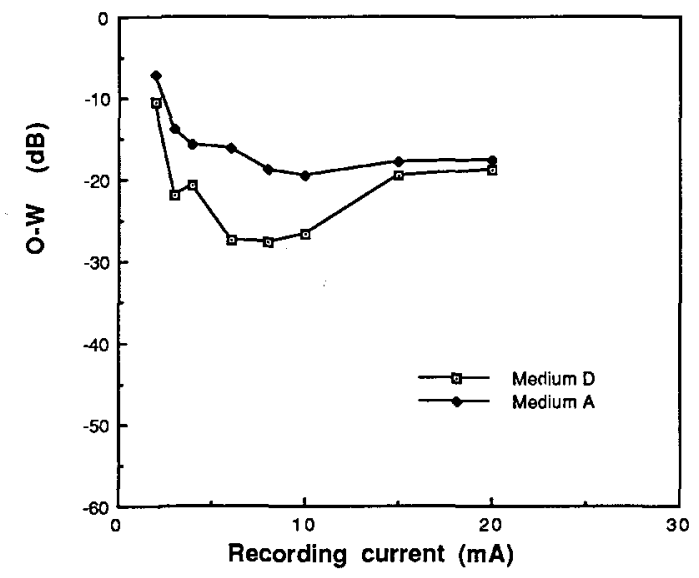

Fig.10 (a) Recording current dependence of O.W characteristics.

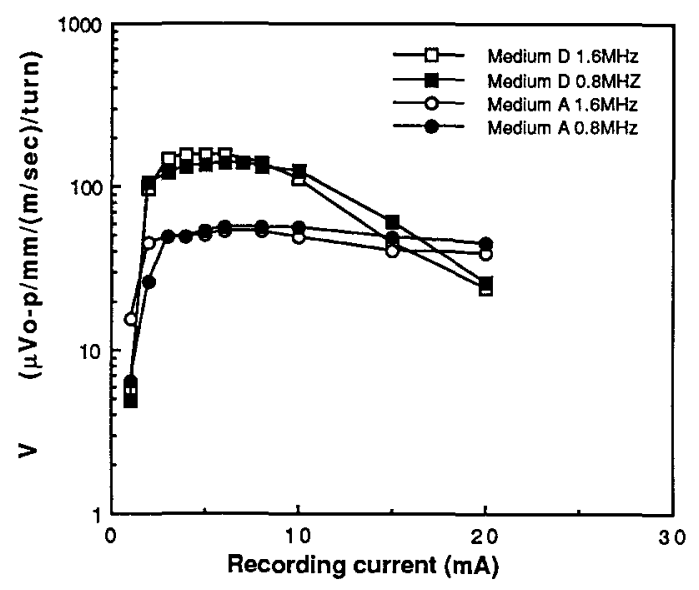

Fig.10 (b) Recording-and reproducing characteristics for recording frequency of $1.6 \mathrm{MHz}$ and $0.8 \mathrm{MHz}$.

broadening of waveform, which resulted in the decrease of $\mathrm{V}$ and D50. It is considered that, for low Hc, interaction between head and high permeable underlayer broadens head field, so broadening magnetization transition. On the other hand, for high $\mathrm{Hc}$, the head field does not broaden even at high recording currents because of low permeability of Fe-Co under-layer. Therefore, as the magnetization transition remains narrow, both $\mathrm{V}$ and $\mathrm{D} 50$ are high. $4 \pi \mathrm{Ms}$ of $\mathrm{Fe}-\mathrm{Co}-\mathrm{O}$ layer influenced on waveform too. The waveform was sharpest at 9000 gauss. $4 \pi \mathrm{Ms}$ larger than 9000 gauss broadens waveform because of low Hc of $\mathrm{Fe}-\mathrm{Co}-\mathrm{O}$. $4 \pi \mathrm{Ms}$ less than 9000 gauss also broadens waveform because of the lack of head capacity for too high $\mathrm{HCl}$ and $\mathrm{Hk}$ of $\mathrm{Fe}-\mathrm{Co}-\mathrm{O}$ layer.

As a result, it is necessary to increase $\mathrm{V}$ and $\mathrm{D} 50$ that $\mathrm{HC}$ of the $\mathrm{Fe}-\mathrm{Co}$ under-layer is higher and $4 \pi \mathrm{Ms}$ of the $\mathrm{Fe}-\mathrm{CO}-\mathrm{O}$ is the optimum value.

\section{ACKNOWLEDGEMENT}

We would like to thank to President S.Iwasaki of Tohoku Institute of Technology and Prof.Y.Nakamura, Assist.Prof.K.Ouchi and Dr.S.Yamamoto of Tohoku University, for their guidance.

\section{REFERENCES}

(1) S.Nasu, K.Matsumoto, K.Hashimoto and K.Saiki: IEEE Trans.Magn., Vol.MAG-23, No.5,pp.2257 (1987).

(2) K.Hashimoto, A.Nakajima, S.Nasu, K.Matsumoto and K.Saiki: Dig.11th Annual Conf.Mag.Jpn. , ( in Japanese). IpA-2 (1987).

(3) S.Nasu, A.Nakajima, K.Matsumoto, K.Hashimoto and K.Saiki:J.Mag.Soc. Jpn., ( in Japanese), Vol.12,No.2,pp. 65 (1988).

(4) M.Isurugi, S.Nasu, K.Matsumoto, A.Nakajima and K.Saiki: J.Mag.Soc. Jpn., ( in Japanese), Vol.13,No.2 ,pp.71 (1989).

(5) N.Watanabe, Y.Ishizaka, K.Kimura and E. Imaoka: IEEE Trans.Magn., Vol.MAG21, No.2,pp.1426 (1985).

(6) O.Kitakami, Y.Ogawa,H.Fujiwara, F. Kugiya and M.Suzuki: IEICE Tech.Rep., (in Japanese), MR88-5 (1988). 